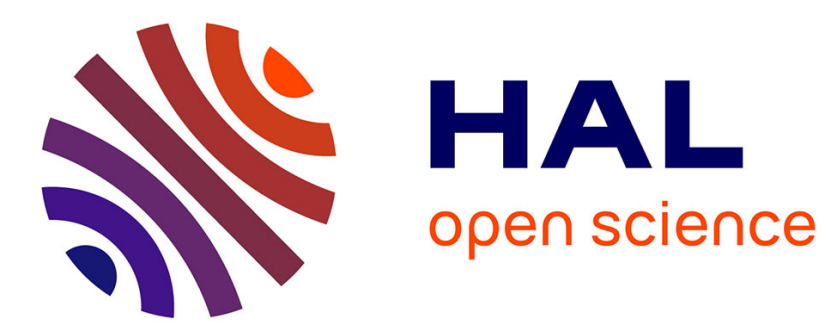

\title{
One-Step Synthesis of O -Benzyl Hydroxamates from Unactivated Aliphatic and Aromatic Esters
}

\author{
Arnaud Gissot, Alessandro Volonterio, Matteo Zanda
}

\section{To cite this version:}

Arnaud Gissot, Alessandro Volonterio, Matteo Zanda. One-Step Synthesis of O -Benzyl Hydroxamates from Unactivated Aliphatic and Aromatic Esters. Journal of Organic Chemistry, 2005, 70 (17), pp.6925-6928. 10.1021/jo0509713 . hal-02475525

\section{HAL Id: hal-02475525 \\ https://hal.science/hal-02475525}

Submitted on 12 Feb 2020

HAL is a multi-disciplinary open access archive for the deposit and dissemination of scientific research documents, whether they are published or not. The documents may come from teaching and research institutions in France or abroad, or from public or private research centers.
L'archive ouverte pluridisciplinaire HAL, est destinée au dépôt et à la diffusion de documents scientifiques de niveau recherche, publiés ou non, émanant des établissements d'enseignement et de recherche français ou étrangers, des laboratoires publics ou privés. 


\title{
Direct Synthesis of $O$-Bn Hydroxamates from Unactivated Aliphatic and Aromatic Esters
}

\author{
Arnaud Gissot, ${ }^{\star}$ Alessandro Volonterio and Matteo Zanda* \\ C.N.R.-I.C.R.M. - sezione "A. Quilico" and Dipartimento C.M.I.C. "G. Natta” - \\ Politecnico di Milano, via Mancinelli 7, I-20131 Milan, Italy \\ matteo.zanda@polimi.it
}

Received Date (will be automatically inserted after manuscript is accepted)

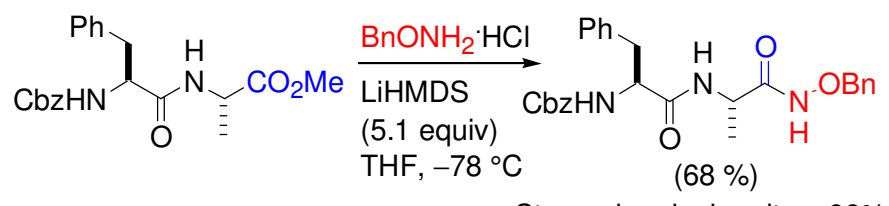

Stereochemical purity $>98 \%$

We have developed a direct, simple and high yielding method for the synthesis of hydroxamate derivatives from a broad range of unactivated esters with the anion of $O$-benzyl-hydroxylamine generated in situ. The reaction takes place in minutes at $-78^{\circ} \mathrm{C}$. Very importantly, the method was successfully utilized with enolizable esters, including chiral $\alpha$-amino acid esters and peptides with no trace of racemization at the $\alpha$ carbon detected.

Hydroxamic acids are of utmost importance in the field of bioorganic and coordination chemistry. They indeed feature excellent bio-availability and count among the best ligands known for most biologically relevant metals. They are for instance found in the structure of numerous drugs which either trigger metal-dependent proteins or are involved in the regulation of intracellular concentrations of metals like iron, and others. ${ }^{1}$ Their biological significance is further illustrated by the numbers of methods that have been-and still are-developed for their chemical synthesis. ${ }^{2}$ These methods overwhelmingly make use of activated forms of carboxylic acids which are reacted with $O$-Bn hydroxylamine to give $O$-Bn hydroxamates - a convenient protected form of free hydroxamic acids-each method differing in the activating group used. Hydrolysis is thus a prerequisite if

${ }^{1}$ (a) Abbenante, G.; Fairlie, D. P. Med. Chem. 2005, 1, 71-104. (b) Whittaker, M.; Floyd, C. D.; Brown, P.; Gearing, A. J. H. Chem. Rev. 1999, 99, 2735-2776. (c) Muri, E. M. F.; Nieto, M. J.; Sindelar, R. D.; Williamson, J. S. Curr. Med. Chem. 2002, 9, 1631-1653. (d) Marmion, C. J.; Griffith, D.; Nola, K. B. Eur. J. Inorg. Chem. 2004, 3003-3016.

${ }^{2}$ For recent examples: (a) De Luca, L.; Giacomelli, G.; Taddei, M. J. Org. Chem. 2001, 66, 2534-2537. (b) Sibi, M. P.; Hasegawa, H.; Ghorpade, S. R. Org. Lett. 2002, 4, 3343-3346. (c) Giacomelli, G.; Porcheddu, A.; Salaris, M. Org. Lett. 2003, 5, 2715-2717 and references therein. readily available precursors like esters are to be converted into hydroxamates. ${ }^{3}$

Besides, many carboxylic acids proved reluctant in the activation step resulting in poor yields in the coupling reaction. A direct conversion of esters into hydroxamic acids should therefore save both the hydrolysis and the potentially troublesome activation steps.

In fact, esters have been successfully reacted with OBn hydroxylamine. To overcome the alleged poor electrophilicity of unactivated aliphatic esters, $\mathrm{AlMe}_{3}$ is yet necessary, the reaction being usually carried out in THF or chlorinated solvents. ${ }^{4}$ This method is quite

${ }^{3}$ (a) Moriyama, H., Tsukida, T., Inoue, Y., Kondo, H., Yoshino, K., Nishimura, S.I. Bioorg. Med. Chem. Lett. 2003, 13, 2737-2740, (b) Cherney, R.J., Duan, J.J.W., Voss, M.E., Chen, L., Wang, L., Meyer, D.T., Wasserman, Z.R., Hardman, K.D., Liu, R.O., Covington, M.B., Qian, M., Mandlekar, S., Christ, D.D., Trzaskos, J.M., Newton, R.C., Magolda, R.L., Wexler, R.R., Decicco, C.P. J. Med. Chem. 2003, 46, 1811-1823, (c) Fujisawa, T., Igeta, K. Odake, S. Morita, Y., Yasuda, J., Morikawa, T. Bioorg. Med. Chem.. 2002, 10, 2569-2581, (d) Kamimura, A., Morita, R., Matsuura, K., Omata, Y., Shirai M. Tetrahedron Lett. 2002, 43, 6189-6191, (e) Durham, B.T., Miller, M.J. Org. Lett. 2002, 4, 135-138.

${ }^{4}$ See for instance: (a) Pirrung, M.C., Chau, J.H.L. J. Org. Chem. 1995, 8084-8085. (b) Durham, T.B., Miller, M.J. J. Org. Chem. 2003, 68, 27-34. (c) Takahashi, H., Hitomi, Y., Iwai, Y., Ikegami, S. J. Am. Chem. Soc. 2000, 122, 2995-3000. (d) Banfi, L.; Cascio, G.; Guanti, G.; Manghisi, E.; Narisano, E.; Riva, R. Tetrahedron 1994, 50, 1196711982. 
limited in scope due to environmental concerns and poor functional group tolerance associated with the use of the hazardous and very reactive $\mathrm{AlMe}_{3}$.

Within the frame of a research project dealing with the synthesis of fluorinated matrix metalloproteinases inhibitors, ${ }^{5}$ we decided to explore the feasibility of a direct and user-friendly protocol for the synthesis of hydroxamates directly from esters and $O-\mathrm{Bn}$ hydroxylamine. In this communication we show that readily available methyl or ethyl esters themselves are excellent electrophiles in the reaction with the anion of $O$ Bn-hydroxylamine in the absence of any activator. ${ }^{6}$ The reaction is operatively simple, takes place very smoothly and efficiently at $-78{ }^{\circ} \mathrm{C}$ in THF, and is very broad in scope.

In a first set of experiments, different organic bases were tested in the reaction of ethyl benzoate with $O$-Bnhydroxylamine (Table 1).

Table 1. Reaction of ethyl benzoate and $O$-Bn-hydroxylamine with different bases.

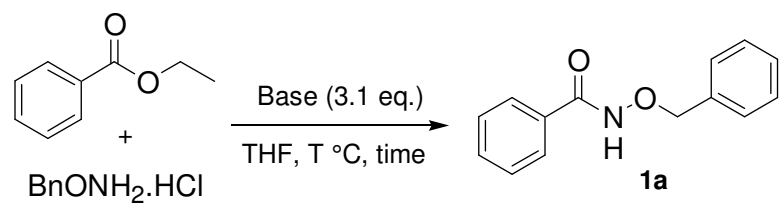

\begin{tabular}{lllll}
\hline Entry & Base & $\mathrm{T}^{\circ} \mathrm{C}$ & Time $(\mathrm{mns})$ & Yield $(\%)$ \\
\hline 1 & TEA & 25 & 360 & 0 \\
2 & KH & -78 & 240 & 0 \\
3 & KH & 25 & 120 & 76 \\
4 & $n$-BuLi & -78 & 20 & $47^{\text {a }}$ \\
5 & NaHMDS & -78 & 20 & 86 \\
6 & LiHMDS & -78 & 10 & 95 \\
\hline \multicolumn{4}{r}{${ }^{a}$ Valerophenone was also obtained (40\% yield) together with a minor }
\end{tabular}
uncharacterized impurity.

In a control reaction with triethylamine as a base, neutral $O$-Bn hydroxylamine proved unreactive at room temperature in THF (entry 1). While no reaction was observed at $-78{ }^{\circ} \mathrm{C}$ in the presence of the stronger $\mathrm{KH}$ base (entry 2), the desired $O$-Bn hydroxamate 1 a was obtained in a satisfactory $76 \%$ yield at room temperature (entry 3). A minimum of 3 equiv. is necessary for this transformation, the first to neutralize hydrochloric acid, the second to form the nucleophilic $N$-centered anion and the third to deprotonate the acidic hydroxamic proton of the product. To check if the absence of reactivity

\footnotetext{
${ }^{5}$ Zanda, M. New. J. Chem. 2004, 28, 1401-1411.

${ }^{6}$ A classical protocol for the synthesis of Weinreb amides consists in the treatment of methyl or ethyl esters with the anion of N,O-dimethyl hydroxylamine. This concept is thus not new but as we shall see later the conditions employed for the synthesis of Weinreb amides are not suitable for the synthesis of hydroamic acids. For examples of synthesis of Weinreb amides using this protocol see: (a) Davis, F.A., Rao, A., Carroll, P.J. Org. Lett. 2003, 5, 3855-3857 (b) Ducharme, Y., Friesen, R.W., Blouin, M., Côté, B., Dubé, D., Ethier, D., Frenette, R., Laliberté, F., Mancini, J.A., Masson, P., Styhler, A., Young, R.N., Girard, Y. Bioorg. Med. Chem. Lett. 2003, 13, 1923-1926, (c) Papaioannou, N., Blank, J.T., Miller, S.J. J. Org. Chem. 2003, 68, 2728-2734, (d) Miller, A.K., Banghart, M.R., Beaudry, C.M., Suh, J.M., Trauner, D. Tetrahedron 2003, 59, 8919-8930, (e) Wender, P.A., Koehler, M.F.T., Sendzik, M. Org. Lett. 2003, 5, 4549-4552.
}

observed at low temperature (entry 2) was the result of either the heterogeneous nature of $\mathrm{KH}$ or the intrinsically low reactivity of the ester, we utilized next commercially available solutions of strong organic bases (entries 4-6). Slow addition of $n$-BuLi at $-78{ }^{\circ} \mathrm{C}$ onto the mixture of ester and $O$-Bn hydroxylamine hydrochloride did produce 1a, although in low yield (entry 4). The attack of $n$-BuLi directly onto the carbonyl competes favorably with the desired coupling reaction as evidenced by the formation of valerophenone in $40 \%$ yield. $^{7}$

We nevertheless found that side reactions are suppressed using sodium and lithium hexamethyldisilazane bases instead. Both afford the desired $O$-Bn hydroxamate $1 \mathrm{a}$ in minutes and in excellent yield at $-78{ }^{\circ} \mathrm{C}$ in THF (entries 5 and 6). The lithium salt of $O$-Bn hydroxylamine proved more reactive over the sodium derivative-perhaps due to its higher solubility in THF at low temperatures-and was therefore used to study the scope of the reaction (Table 2).

Electron rich $\left(\mathrm{R}^{1}=\mathrm{OMe}\right)$ or poor $\left(\mathrm{R}^{1}=\mathrm{F}\right)$ aromatics gave the desired products $\mathbf{1 b}$ and $\mathbf{1 c}$ respectively, in good yields. Surprisingly, the nitro-substituted 1d was obtained in $37 \%$ yield only from the highly activated 4-nitro methyl benzoate. ${ }^{8}$ Heteroaromatic furyl and nicotinic esters gave 1e and 1f in good yields. No aza-Michael addition of the nucleophile was observed with methyl cinnamoate, the desired hydroxamic acid derivative $\mathbf{1 g}$ being obtained quantitatively. Quite surprisingly, enolizable substrates were also found very reactive provided an additional equivalent of base was used. This additional equivalent of base is necessary to deprotonate the acidic $\alpha$-proton in that case. ${ }^{9}$ For instance, ethyl hydrocinnamate reacted virtually instantaneously with $O$ Bn hydroxylamine and 4.1 equiv. of LiHMDS at $-78{ }^{\circ} \mathrm{C}$ in THF affording the hydroxamate $\mathbf{1 h}$ quantitatively. Cyclic enolizable esters like $\alpha$-methyl $\beta$-lactone and $\gamma$ lactone also reacted effectively affording the hydroxamates $\mathrm{HOCH}_{2} \mathrm{CH}\left(\mathrm{CH}_{3}\right) \mathrm{CONHOBn}$ (1i) and $\mathrm{HO}\left(\mathrm{CH}_{2}\right)_{2} \mathrm{CH}\left(\mathrm{CH}_{3}\right) \mathrm{CONHOBn}(\mathbf{1 j})$. Interestingly, chiral $O$-Bn hydroxamate $\mathbf{1 k}$ was obtained in good yields without noticeable racemization at the $\alpha$ position $\left({ }^{1} \mathrm{H}\right.$ and ${ }^{13}$ C NMR analysis).

Table 2. Reaction of $O$-Bn-hydroxylamine with different esters under optimized conditions.

${ }^{7}$ Since $n$-BuLi is always present in excess to deprotonate the final hydroxamate, this side reaction is unfortunately unavoidable even if the ester is added last to the anion of $O$-Bn-hydroxylamine (result not shown). In turn, this result shows that if the use of $n-\mathrm{BuLi}$ or Grignard reagents to deprotonate $\mathrm{N}, \mathrm{O}$-dimethylhydroxylamine constitutes a powerful method to synthesize Weinreb amides from esters, this strategy cannot be utilized with $O$-Bn-hydroxylamine (which has an additional proton) to form hydroxamic acid derivatives, as addition of the base to the ester will always compete with deprotonation.

${ }^{8}$ An intense red color was observed upon addition of the ester to the lithiated $O$-Bn hydroxylamine. This color might indicate the formation of a charge transfer complex that perturbs the reaction. Unfortunately, an even poorer yield was obtained with $\mathrm{KH}$ at $20{ }^{\circ} \mathrm{C}$ instead of LiHMDS and no reaction was observed with TEA ( 5 equiv.) in refluxing THF.

${ }^{9}$ Deprotonation $\alpha$ to the ester does take place as evidenced by the formation of the Claisen condensation product from ethyl hydrocinnamate when LiHMDS was slowly added to the mixture of ester and O-benzylhydroxylamine at $-78^{\circ} \mathrm{C}$ in THF (result not shown). 


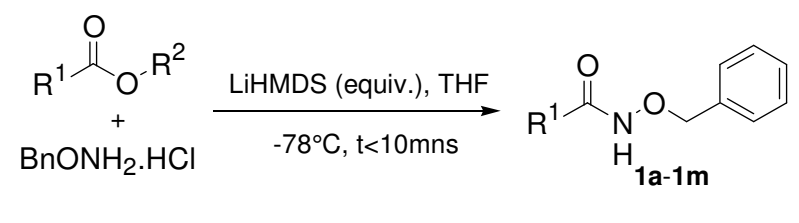

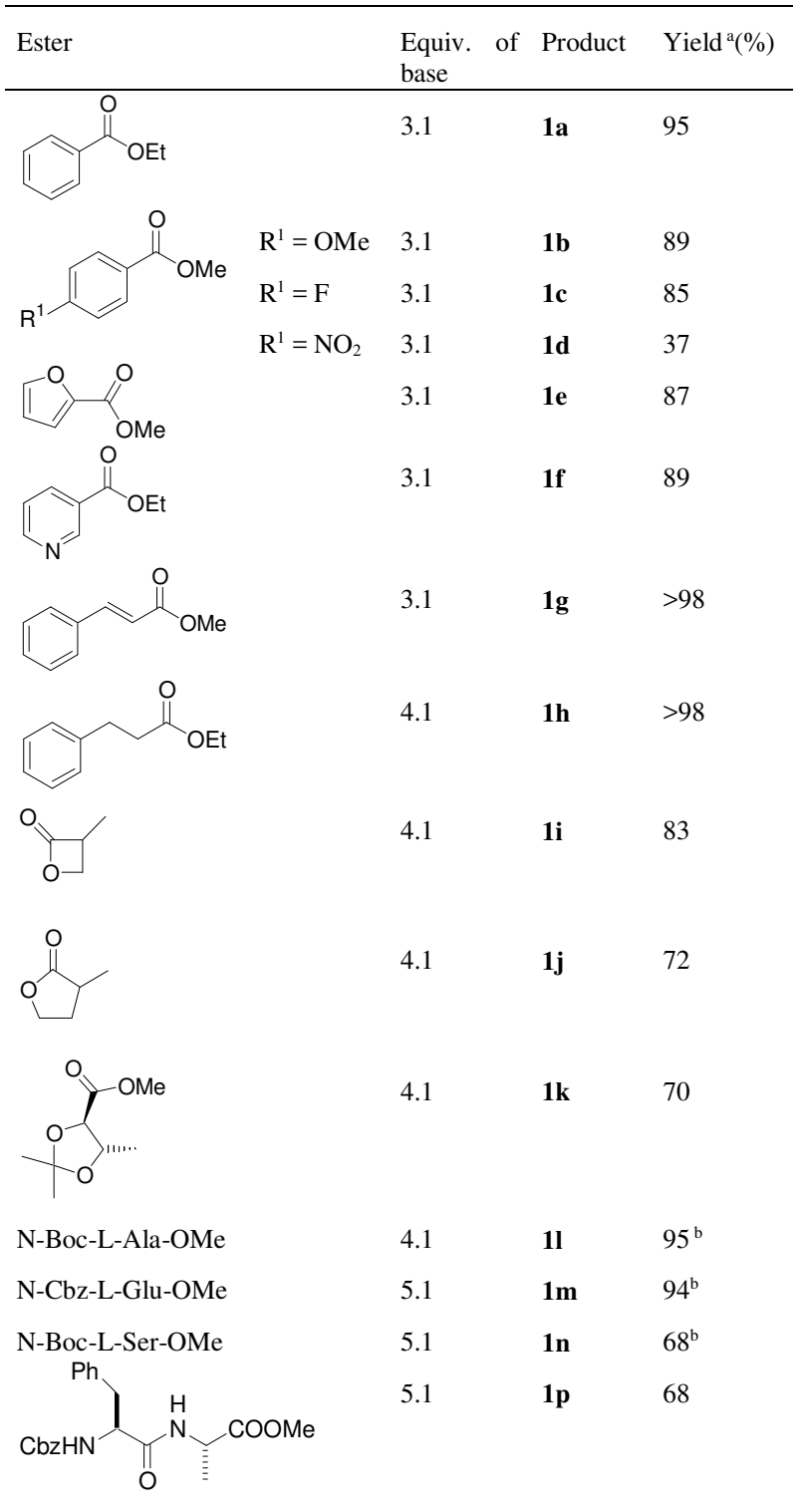

${ }^{a}$ Isolated yield of pure product. All reactions carried out on a one millimole scale. ${ }^{\mathrm{b}}$ Enantiomerically pure product.

Given the significance of amino acid and peptide derived hydroxamates, the method was also probed with such derivatives like $N$-Boc-Ala, $N$-Cbz-Glu and $N$-BocSer methyl esters. These substrates proved very reactive at $-78{ }^{\circ} \mathrm{C}-$ no protection of the free hydroxy and carboxylic positions was required-affording the corresponding $O$-Bn hydroxamates $\mathbf{1 1}, \mathbf{1 m}$ and $\mathbf{1 n}$, respectively, in good to excellent yields. ${ }^{10}$ Quite

${ }^{10}$ More polar hydroxamic acid derivatives are usually obtained in low yields after flash chromatography. We usually overcame this problem simply by triturating the crude in hexane to afford the desired product analytically pure. This was for instance done for derivatives $\mathbf{1 j}$ - surprizingly, and to our delight, the stereochemistry of the $\alpha$-amino acidic carbon was preserved. ${ }^{11}$ The preservation of the stereochemical purity and the fact that 4.1 equiv. of LiHMDS (or 5.1 in the case of Glu which has an additional acidic proton) are sufficient to perform the reaction strongly suggest that deprotonation at the $\alpha$ carbon does not take place. ${ }^{12}$ The method could be extended to peptidic esters as well, as demonstrated by the formation of the $O$-Bn hydroxamate Cbz-Phe-AlaNHOBn (1p) from the corresponding dipeptide methyl ester. In this case too, no trace of epimerization was detected despite the use of 5.1 equiv. of base $\left({ }^{1} \mathrm{H}\right.$ and ${ }^{13} \mathrm{C}$ NMR analysis).

In conclusion, we have disclosed a simple, straightforward and high yielding method for the direct synthesis of $O$-Bn hydroxamates from a broad range of unactivated esters. Despite the alleged poor reactivity of these substrates, they react in minutes at $-78{ }^{\circ} \mathrm{C}$ with the anion of $\mathrm{O}-\mathrm{Bn}$ hydroxylamine. Very interestingly and importantly, enolizable esters, $\alpha$-amino acid esters and peptide esters were also successfully reacted with no trace of racemization at the $\alpha$ carbon in spite of the strongly basic conditions. Given its simplicity and efficiency, we hope this method will become the method of choice for the preparation of hydroxamates and hydroxamic acids.

Acknowledgment We thank the European Commission (IHP Network grant "FLUOR MMPI" HPRN-CT-2002-00181), MIUR (Cofin 2004, Project "Polipeptidi Bioattivi e Nanostrutturati"), Politecnico di Milano, and C.N.R. for economic support.

Supporting Information Available ("Supporting Information" on the Styles toolbar).

\footnotetext{
${ }^{11}$ In order to assess the enantiomeric purity, 1n was derivatized with (S)- $\alpha$-methylphenylacetic acid affording the corresponding ester in d.e. $>98 \%$ (95\% yield). The enantiomeric purity of 11 was assessed by polarimetric analysis, which showed an $[\alpha]_{D}$ identical to that reported in the literature for the enantiopure compound (see Supporting Information).

${ }^{12}$ Prior deprotonation of the NH-Cbz or NH-Boc groups may prevent the amino acid from undergoing additional deprotonation at the chiral center.
} 